\title{
Efeito da Idade dos Frangos de Corte sobre a Atividade Enzimática e Digestibilidade dos Nutrientes do Farelo de Soja e da Soja Integral
}

\author{
Nilva Kazue Sakomura ${ }^{1}$, Margarete Del Bianchi², João Martins Pizauro Jr. ${ }^{3}$, Marcos Barcelos \\ Café ${ }^{4}$, Ednardo Rodrigues Freitas ${ }^{5}$
}

RESUMO - Esse trabalho visou investigar o efeito da idade de aves sobre a digestibilidade dos nutrientes da soja integral extrusada (SIE), soja integral tostada à vapor (SITV) e farelo de soja com óleo (FSO) na produção de enzimas digestivas do pâncreas. Cinco ensaios de digestibilidade foram conduzidos com frangos de corte de uma, duas, três, quatro e seis semanas de idade. Foi utilizada a metodologia de coleta total de excretas. A atividade das enzimas amilase e tripsina pancreática aumentou linearmente com a idade das aves, assim como o crescimento alométrico do pâncreas. A maior taxa de crescimento ocorreu na segunda semana, coincidindo com a fase de maior aumento da atividade das enzimas digestivas. Entretanto, para a atividade da lipase, o efeito da idade foi diferente para cada alimento. Para aves alimentadas com SITV, a atividade dessa enzima cresceu linearmente com a idade, enquanto nas alimentadas com SIE, FSO e ração, o efeito foi quadrático. Os coeficientes de digestibilidade da matéria seca e extrato etéreo e os valores de energia metabolizável dos tipos de sojas variaram em proporções diferentes em função da idade. Também, observou-se correlação positiva entre a digestibilidade do extrato etéreo e a atividade de lipase. Os valores de energia metabolizável aparente corrigida (EMAn) e verdadeira corrigida (EMVn) determinados para a SIE apresentaram comportamento quadrático em função da idade, ocorrendo aumento da energia metabolizável (EM) até a $3^{\mathrm{a}}$ semana de idade e diminuindo a partir da $4^{\mathrm{a}}$ semana. Entretanto, a EM da SITV, FSO e da ração não foi afetada pela idade da ave. O aproveitamento da energia dos alimentos varia com a idade das aves, em função de sua dependência da atividade enzimática.

Palavras-chave: digestibilidade dos nutrientes, enzimas pancreáticas, soja integral processada

\section{Effect of Age on Enzyme Activity and Nutrients Digestibility for Broilers Fed Soybean Meal and Full Fat Soybean}

\begin{abstract}
This work aimed to investigate the effect of broilers age in the digestibility of nutrients in extruded and toasted full fat soybean (EFFS and TFFS) and soybean meal plus oil (SMO), and in the production of digestive pancreatic enzymes. Five digestibility assays were carried out with broilers of one, two, three, four , and six weeks of age. Total collected excreta methodology was applied. The activities of amylase and pancreatic trypsin enzymes increased linearly with the broilers age, as well as the allometric growth of the pancreas. The highest allometric growth ratio occurred in the second week, coincidentally with the period of increasing activity of the digestive enzymes. However, for lipase activity, distinct age affect was found for each feeds. For birds fed on TFFS, the enzyme activity increased linearly with age, while those fed on EFFS, SMO, and concentrate a quadratic effect was observed. The digestibility coefficients for dry matter and ether extract and the soybeans metabolizable energy (ME) varied at different proportions by age. A positive correlation between ether extract digestibility and lipase activity was also observed. The results of corrected apparent and actual metabolizable energy for EFFS presented a quadratic profile in function of age, increasing ME up to the third week and decreasing after this period. However, ME of TFFS, SMO and concentrate was not affected by chicks age. The nutrient digestibility of feedstuffs varies with chicks age, due to the different enzymatic activities.
\end{abstract}

Key Words: nutrient digestibility, pancreatic enzyme, processed soybean

\section{Introdução}

O uso de rações com alta densidade energética tornou-se comum tanto na avicultura de corte quanto na de postura em função das exigências nutricionais de aves mais produtivas. $\mathrm{O}$ aumento da energia nas rações tem sido feito incorporando-se óleo às rações formuladas principalmente à base de milho e farelo de soja.

A utilização da soja integral processada pelo calor em substituição ao farelo de soja e ao óleo nas rações de aves em determinadas situações tem sido viável, por ser fonte de proteína de alta qualidade e

\footnotetext{
1 Profa. do Departamento de Zootecnia - FCAV/UNESP-Jaboticabal, SP (sakomura@fcav.unesp.br).

2 Profa. da Faculdade de Agronomia "Manoel Carlos Gonçalves" - Pinhal, SP.

3 Prof. do Departamento de Tecnologia - FCAVIUNESP-Jaboticabal.

4 Prof. Universidade Federal de Goiás - Goiânia, GO.

5 Aluno do curso de Pós-graduação em Zootecnia/FCAV/UNESP/Jaboticabal.
} 
contribuir com o aumento de sua densidade energética. Entretanto, a necessidade de processamento térmico para a inativação dos fatores antinutricionais faz com que esta técnica continue sendo estudada, em função das variações nutricionais promovidas pelo processamento a que foi submetida. Entre os processamentos mais usados estão a tostagem pelo vapor e a extrusão.

Alguns estudos têm demonstrado a influência da idade da ave no processo de digestão e absorção de gorduras. Nas primeiras semanas de idade da ave, a digestibilidade dos lipídeos é menor e aumenta com a idade (Whitehead \& Fisher, 1975; Katangole \& March 1980; Sell et al., 1986). Entre os fatores que afetam a digestão de lipídeos, estão os processos de adaptação e maturação das células absortivas do intestino (Moran Jr, 1985), a maturação dos órgãos para a produção e liberação de enzimas digestivas e também aqueles pertinentes aos diferentes tipos de alimento, sua natureza, composição química e a complexação entre os mesmos.

Considerando os fatores abordados, o objetivo do presente estudo foi verificar o efeito da idade da ave sobre a digestibilidade da energia, do extrato etéreo e da matéria seca da Soja Integral Extrusada (SIE), da Soja Integral Tostada pelo Vapor (SITV) e do Farelo de Soja com incorporação de Óleo (FSO) e quantificar a atividade das enzimas digestivas pancreáticas em frangos de corte.

\section{Material e Métodos}

O experimento foi conduzido no aviário experimental da FCAV/UNESP /Jaboticabal. Foram criados 2.000 pintos de corte de um dia da marca comercial Hubbard, metade de cada sexo. As aves foram alojados em um galpão convencional, em piso com cama de maravalha, em uma densidade de 10 aves/ $\mathrm{m}^{2} \mathrm{e}$ à medida que os ensaios foram conduzidos as aves foram retiradas e levadas para as instalações experimentais.

\section{Controle de qualidade dos alimentos}

Antes de serem testados, os alimentos foram submetidos a análises de controle de qualidade no Laboratório de Nutrição Animal e de Tecnologia de Produtos de Origem Animal/FCAV/UNESP/ Jaboticabal.

A atividade ureática e a solubilidade de proteína foram determinadas conforme metodologias propostas pela ANFAR (1992); a atividade do inibidor da tripsina, segundo o método descrito por Kakade et al. (1969), utilizando-se a caseína como substrato; e a atividade hemaglutinante, segundo metodologia descrita por Junqueira \& Sgarbieri (1981). O título hemaglutinante foi definido como o inverso da maior diluição capaz de promover aglutinação de hemáceas nas condições do teste.

\section{Ensaios de digestibilidade}

Os ensaios de digestibilidade foram conduzidos na $1^{\mathrm{a}}, 2^{\mathrm{a}}, 3^{\mathrm{a}}, 4^{\mathrm{a}}$ e $6^{\mathrm{a}}$ semanas de idade das aves utilizando-se a metodologia de coleta total de excretas. Cada ensaio teve duração de sete dias, sendo três de adaptação às dietas experimentais e quatro de coleta de excretas.

Os ensaios da $1^{\text {a }}$ à $4^{\text {a }}$ semanas de idade foram realizados em baterias dotadas de aquecimento, com comedouros e bebedouros do tipo calha e bandejas coletoras de excretas. Na $6^{\text {a }}$ semana, o ensaio foi realizado em gaiolas metálicas, também equipadas com bebedouros e comedouros do tipo calha, com bandejas para coleta de excretas.

Nos quatro primeiros ensaios, foram utilizadas 250 aves em cada ensaio, retiradas semanalmente do lote criado em piso. No 5 o ensaio, foram utilizadas 150 aves.

Em todos os ensaios, as aves foram distribuídas ao acaso em quatro tratamentos com cinco repetições por tratamento, cada uma composta por cinco machos e cinco fêmeas e três de cada sexo no 5 o ensaio. Simultaneamente, 50 aves distribuídas em cinco repetições de 10 aves foram mantidas em jejum por 36 horas, para esvaziamento do trato digestório, e, por mais 48 horas, para coleta das perdas endógenas e metabólicas.

Os tratamentos consistiram em três rações-teste e uma ração-referência. Cada ração-teste era composta por $60 \%$ da ração-referência e $40 \%$ de um dos alimentos avaliados: soja integral tostada pelo vapor (SITV), soja integral extrusada (SIE) e mistura farelo de soja e óleo de soja (FSO).

Foram formuladas duas rações-referência (Tabela 1) para as fases de 1 a 21 dias e de 22 a 42 dias de idade, ambas compostas por milho e farelo de soja sem adição de óleo. A mistura farelo de soja e óleo foi feita na proporção $80 \%$ de farelo com $20 \%$ de óleo, com base na matéria natural.

As coletas de excretas foram feitas duas vezes ao dia, no início da manhã e no final da tarde. Uma vez coletadas, foram acondicionadas em sacos plásticos, identificadas por repetição e congeladas. 
No final de cada período experimental, foram determinadas as quantidades de ração consumida e o total de excretas produzido. Após descongelamento à temperatura ambiente, as excretas de cada repetição foram homogeneizadas para a retirada de uma amostra, que foi seca em estufa de ventilação forçada a $55^{\circ} \mathrm{C}$, por 72 horas, a fim de promover a pré-secagem e determinar peso da amostra seca ao ar. Em seguida, as amostras foram processadas em moinho tipo faca, com peneira de 1 mm e encaminhadas ao laboratório, junto com amostras das rações experimentais, para determinação de matéria seca, nitrogênio e extrato etéreo, segundo metodologia descrita por Silva (1981).
A energia bruta foi determinada em bomba calorimétrica adiabática (Modelo 1263, PARR).

Simultaneamente aos ensaios de digestibilidade, 10 aves por tratamento foram submetidas as mesmas condições de manejo e alimentação, para coleta do pâncreas.

Após 12 horas de jejum alimentar, três aves de cada tratamento foram pesadas e sacrificadas para a retirada do pâncreas, que foi pesado, congelado em nitrogênio líquido e armazenado a $-80^{\circ} \mathrm{C}$.

Para determinação do crescimento alométrico do pâncreas, foi utilizada equação descrita por Fisher (1984): crescimento $=\left(\mathrm{PP}_{\mathrm{x}} / \mathrm{PPi}\right) /\left(\mathrm{PC}_{\mathrm{x}} / \mathrm{PCi}\right)$, em que

Tabela 1 - Composição percentual e calculada das rações-referência

Table 1 - Percentage and calculed composition of the refence diet

\begin{tabular}{|c|c|c|}
\hline $\begin{array}{l}\text { Ingredientes (\%) } \\
\text { Ingredient }\end{array}$ & $\begin{array}{l}1 \text { a } 21 \text { dias de idade } \\
1 \text { to } 21 \text { days of age }\end{array}$ & $\begin{array}{l}22 \text { a } 42 \text { dias de idade } \\
22 \text { to } 42 \text { days of age }\end{array}$ \\
\hline Milho & 57,46 & 64,50 \\
\hline Corn & & \\
\hline $\begin{array}{l}\text { Farelo de soja } \\
\text { Soybean meal }\end{array}$ & 38,44 & 31,67 \\
\hline $\begin{array}{l}\text { Fosfato bicálcico } \\
\text { Dicalcium phosphate }\end{array}$ & 2,11 & 1,86 \\
\hline $\begin{array}{l}\text { Calcário } \\
\text { Limestone }\end{array}$ & 0,95 & 1,05 \\
\hline $\begin{array}{l}\text { Sal } \\
\text { Salt }\end{array}$ & 0,30 & 0,30 \\
\hline $\begin{array}{l}\text { DL - Metionina } \\
\text { DL-Methionine }\end{array}$ & 0,04 & 0,02 \\
\hline $\begin{array}{l}\text { Mixtura vitamínica e mineral } \\
\text { Vitamin and mineral mix }\end{array}$ & $0,70^{(1)}$ & $0,60^{(2)}$ \\
\hline TOTAL & 100,00 & 100,00 \\
\hline $\begin{array}{l}\text { Composição calculada } \\
\text { Calculated composition } \\
\end{array}$ & & \\
\hline $\begin{array}{l}\text { Energia metabolizável (kcal/kg) } \\
\text { Metabolizable energy }\end{array}$ & 2.840 & 2.930 \\
\hline $\begin{array}{l}\text { Proteína bruta (\%) } \\
\text { Crude protein }\end{array}$ & 22,40 & 19,95 \\
\hline $\begin{array}{l}\text { Cálcio (\%) } \\
\text { Calcium }\end{array}$ & 1,30 & 0,96 \\
\hline $\begin{array}{l}\text { Fósforo disponível (\%) } \\
\text { Available phosphorus }\end{array}$ & 0,50 & 0,45 \\
\hline $\begin{array}{l}\text { Lisina }(\%) \\
\text { Lysine }\end{array}$ & 1,23 & 1,05 \\
\hline $\begin{array}{l}\text { Metionina + Cistina (\%) } \\
\text { Methionine + Cystine }\end{array}$ & 0,90 & 0,90 \\
\hline
\end{tabular}

${ }^{1}$ Conteúdo/kg (content/kg): Fe, 10.000 mg; Co, 15.000 mg; I, 250 mg; Se, 50 mg; Mn, 24.000 mg; Z, 20.000 mg; Vit. A, 300.000 U.I.; Vit. D, 100.000 mg; Vit. E, 4000 mg; Vit. K, 98 mg: Vit. B1, 400 mg; Vit. B2, 1.320 mg; Vit. B12, 4000 mcg; Ac. pantotênico (acid pantothenic) 2000 mg; Niacina (niacine) 20.000 mg; Ác. fólico (folic acid) 100 mg; Colina (choline)100.000 mg; Lisina (lysine) 2\%; Met+Cis (meth+cys) $32 \%$.

2 Conteúdo/kg (content/kg): Fe, 10.000 mg; Co, 15.000 mg; I, 250 mg; Se, 50 mg; Mn, 24.000 mg; Z, 20.000 mg; Vit. A, 300.000 U.I.; Vit. D, 100.000 mg; Vit. E, 4000 mg; Vit. K, 98 mg: Vit. B1, 400 mg; Vit. B2, 720 mg; Vit. B12, 4000 mcg; Ac. pantotênico (acid panthotenic) 2000 mg; Niacina (niacine) 20.000 mg; Ác. fólico (folic acid) 100 mg; Colina (choline) 100.000 mg; Lisina (lysine) $2 \%$; Met+Cis (met+cys) $18 \%$. 
$\mathrm{PP}_{\mathrm{x}}=$ peso do pâncreas da ave na idade $\mathrm{x} ; \mathrm{PPi}=$ peso do pâncreas da ave com um dia de idade; $\mathrm{PC}_{\mathrm{x}}=$ peso corporal da ave na idade $\mathrm{x} ; \mathrm{PCi}=$ peso corporal da ave com um dia de idade.

A extração do zimogênio e determinação da atividade das enzimas foram feitas no Laboratório de Bioquímica do Departamento de Tecnologia da FCAV/ UNESP/Jaboticabal. O pâncreas foi descongelado à temperatura ambiente, pesado e homogeneizado, utilizando-se tampão Tris-HCl 50 mM, pH 8,0 contendo $\mathrm{CaCl}_{2} 50 \mathrm{mM}$, à proporção de $1 / 20$ (peso/volume), em banho de gelo. $\mathrm{O}$ extrato bruto foi centrifugado a $14.000 \mathrm{xg}$ por 30 minutos sob refrigeração a $4^{\circ} \mathrm{C}$, filtrado em lã de vidro. Do material filtrado foram retiradas alíquotas, armazenadas a $-20^{\circ} \mathrm{C}$ para determinações posteriores.

A determinação da atividade da lipase foi feita por titulometria, segundo o método de Sarda \& Desnuele (1958), realizada em triplicatas e velocidades iniciais constantes durante pelo menos 3 horas, assegurando-se hidrólise de substrato sempre inferior a 5\%. A unidade de atividade enzimática de lipase foi definida e expressa como a quantidade de lipase que libera 1 mmol de ácido graxo por minuto, nas condições-padrão do teste.

Após ativação do tripsinogênio, a atividade da tripsina foi determinada descontinuamente a $37^{\circ} \mathrm{C}$, com a liberação da p-nitroanilida ( $\mathrm{e}=9620 \mathrm{M}^{-1} \mathrm{~cm}^{-1}$, 410 nm), em um espectrofotômetro HITACHI U-2000, segundo Kakade et al. (1974). Em cada experimento, foram incluídos controles sem adição de enzima, para se estimar a hidrólise espontânea do substrato. As determinações foram feitas em triplicatas, sendo que as velocidades iniciais permaneceram constantes durante pelo menos 30 minutos, com menos de $5 \%$ do substrato sendo hidrolisado e uma unidade (U) de enzima definida como 1 mmol de p-nitroanilida liberada por minuto nas condições do teste.

A atividade de $\alpha$-amilase pancreática foi determinada descontinuamente a $37^{\circ} \mathrm{C}$, de acordo com o procedimento descrito por Bernfeld (1955) e uma unidade de atividade enzimática de amilase foi definida e expressa como a quantidade de enzima que libera $1 \mathrm{mmol}$ de maltose/minuto/nas condiçõespadrão do teste.

A dosagem de proteína foi feita de acordo com o método descrito por Hartree (1972), usando-se soroalbumina bovina fração V como padrão.

Os dados foram analisados pelo programa ESTAT (UNESP/Jaboticabal), segundo o modelo fatorial
$4 \times 5$, sendo estudados quatro alimentos (SIE, SITV, FSO e ração-referência) e cinco idades $\left(1^{\mathrm{a}}, 2^{\mathrm{a}}, 3^{\mathrm{a}}, 4^{\mathrm{a}}\right.$ e $6^{\text {a }}$ semanas). A comparação das médias foi realizada pelo teste Tukey a 5\%. Também foram feitas análises de regressão para o efeito da idade em cada tipo de soja.

\section{Resultados e Discussão}

Os valores de atividade ureática (Tabela 2) encontram-se dentro da faixa ecomendada pela ANFAR (1985), enquanto os valores de solubilidade de proteína estiveram acima de $70 \%$, indicando que o processamento térmico foi adequado para inativar os fatores antinutricionais sem superaquecimento (Araba \& Dale 1990a,b).

Os maiores valores das atividades de inibidor da tripsina e hemaglutinante foram obtidos para a SITV.

Não houve interação entre os tipos de soja e idade da ave no crescimento alométrico do pâncreas (Tabela 3). Entretanto, a idade das aves influenciou significativamente essa variável.

A taxa de crescimento do pâncreas diminuiu linearmente com a idade da ave $(\mathrm{Y}=2,30-0,31 \mathrm{x}$; $\left.\mathrm{R}^{2}=0,99\right)$. O valor máximo observado foi de $1,98 \mathrm{e}$ ocorreu no $7^{\circ}$ dia de idade. A partir dos 14 dias, a taxa foi diminuindo em média 0,30 por semana até a $4^{\text {a }}$ semana de idade. Entre a $4^{\text {a }}$ e $6^{\text {a }}$ semanas houve queda mais brusca, passando de 1,12 para 0,39. Segundo Krogdhal \& Sell (1989), Nitsan et al. (1991a,b) e Nir et al. (1993), o maior crescimento desse órgão ocorre entre a $1^{\text {a }}$ e $2^{\text {a }}$ semanas de idade das aves, reduzindo em seguida.

O crescimento alométrico do pâncreas acompanha a curva de crescimento do frango, porém sua taxa de crescimento é maior nas primeiras semanas de idade das aves, uma vez que nessa fase ocorre a maturação fisiológica de seus órgãos digestivos, essencial na produção e liberação dos zimogênios das enzimas digestivas (Moran Jr., 1985). Esta relação pode ser verificada nas determinações da atividade das enzimas pancreáticas realizadas nesse experimento.

Os valores de atividade da amilase são apresentados na Tabela 4. Não foi observada interação significativa entre a idade das aves e os alimentos testados para a atividade dessa enzima e também não foi registrado efeito dos alimentos.

Aumento linear da atividade da amilase foi verificado com o avançar da idade da ave ( $\mathrm{Y}=8,44+$ $22,73 x, R^{2}=0,99$ ). Proporcionalmente, a fase de maior atividade da amilase foi entre a $1^{\text {a }}$ e a $2^{\text {a }}$ semanas de

\footnotetext{
R. Bras. Zootec., v.33, n.4, p.924-935, 2004
} 
Tabela 2 - Atividade ureática, solubilidade da proteína, atividade do inibidor da tripsina e hemaglutinante do farelo de soja e das sojas integrais processadas

Table 2 - Ureatic activity, protein solubility, antitrypsin and hemagglutinin activity of soybean meal and full fat soybeans

\begin{tabular}{lcccc}
\hline $\begin{array}{l}\text { Soja } \\
\text { Soybean }\end{array}$ & $\begin{array}{c}\text { A.U. } \\
(\text { dif.pH) }\end{array}$ & $\begin{array}{c}\text { S.P.(2) } \\
(\%)\end{array}$ & $\begin{array}{c}\text { A.I.T. }{ }^{(3)} \\
\text { (UTI/mg am.) }\end{array}$ & $\begin{array}{c}\text { A.H. }^{(4)} \\
\text { (UH/mg am.) }\end{array}$ \\
\hline $\begin{array}{l}\text { Farelo de soja } \\
\begin{array}{l}\text { Soybean meal } \\
\text { Tostada }\end{array}\end{array}$ & 0,06 & 80,40 & 18,26 & 95 \\
$\begin{array}{l}\text { Toasted full fat soybean } \\
\begin{array}{l}\text { Extrusada } \\
\text { Extruded full fat soybean }\end{array}\end{array}$ & 0,05 & 81,60 & 52,20 & 320 \\
& 0,10 & 82,81 & 20,16 & 87
\end{tabular}

${ }_{1}^{1}$ Diferença de $\mathrm{pH}$ (difference of $\left.\mathrm{pH}\right)$.

2 Solubilidade de proteína em $\mathrm{KOH}$ (Protein solubility at $\mathrm{KOH}$ ).

3 Atividade do inibidor da tripsina (Trypisin inhibitor actitivity).

${ }^{4}$ Atividade hemaglutinante (Hemagglutinin actitivity).

Tabela 3 - Crescimento alométrico do pâncreas (1) segundo os tipos de soja e idade das aves

Table 3 - Effect of age and full fat soybeans on allometric growth of pancreas (1)

\begin{tabular}{|c|c|c|c|c|c|c|}
\hline \multirow[t]{2}{*}{$\begin{array}{l}\text { Soja } \\
\text { Soybean }\end{array}$} & \multicolumn{5}{|c|}{$\begin{array}{c}\text { Idade (dias) } \\
\text { Age (days) }\end{array}$} & \multirow{2}{*}{$\begin{array}{c}\text { Média } \\
\text { Mean } \\
35-42\end{array}$} \\
\hline & & $1-7$ & $8-14$ & $15-21$ & $22-28$ & \\
\hline $\begin{array}{l}\text { Farelo de soja + óleo } \\
\text { Soybean meal + oil }\end{array}$ & 1,95 & 1,41 & 1,50 & 0,94 & 0,40 & 1,24 \\
\hline $\begin{array}{l}\text { Tostada } \\
\text { Toasted FFS }\end{array}$ & 1,85 & 1,69 & 1,29 & 1,11 & 0,35 & 1,26 \\
\hline $\begin{array}{l}\text { Extrusada } \\
\text { Extruded FFS }\end{array}$ & 2,35 & 1,63 & 1,31 & 1,35 & 0,40 & 1,41 \\
\hline $\begin{array}{l}\text { Ração referência } \\
\text { Reference diet }\end{array}$ & 1,78 & 1,73 & 1,48 & 1,09 & 0,41 & 1,30 \\
\hline $\begin{array}{l}\text { Média } \\
\text { Mean }\end{array}$ & 1,98 & 1,62 & 1,39 & 1,12 & 0,39 & \\
\hline
\end{tabular}

${ }^{1}$ Valores expressos em números absolutos (Absolute values).

$\mathrm{CV}=15,15 \%$.

Tabela 4 - Atividade da amilase pancreática (U/mg de proteína), segundo os tipos de soja e a idade das aves

Table 4 - Effect of age and full fat soybeans on the amylase activity (U/mg of protein)

\begin{tabular}{|c|c|c|c|c|c|c|}
\hline \multirow[t]{2}{*}{$\begin{array}{l}\text { Soja } \\
\text { Soybean }\end{array}$} & \multicolumn{5}{|c|}{$\begin{array}{l}\text { Idade (dias) } \\
\text { Age (days) }\end{array}$} & \multirow[t]{2}{*}{$\begin{array}{l}\text { Média } \\
\text { Mean }\end{array}$} \\
\hline & $1-7$ & 8-14 & $15-21$ & $22-28$ & $35-42$ & \\
\hline $\begin{array}{l}\text { Farelo de soja + óleo } \\
\text { Soybean meal + oil }\end{array}$ & 13,16 & 34,21 & 53,82 & 92,51 & 128,85 & 64,51 \\
\hline $\begin{array}{l}\text { Tostada } \\
\text { Toasted FFS }\end{array}$ & 17,16 & 27,73 & 45,23 & 71,26 & 136,73 & 59,62 \\
\hline $\begin{array}{l}\text { Extrusada } \\
\text { Extruded FFS }\end{array}$ & 13,89 & 46,49 & 52,11 & 80,32 & 88,93 & 56,62 \\
\hline $\begin{array}{l}\text { Ração-referência } \\
\text { Reference diet }\end{array}$ & 14,71 & 26,83 & 84,95 & 116,23 & 155,52 & 79,65 \\
\hline $\begin{array}{l}\text { Média } \\
\text { Mean }\end{array}$ & 14,73 & 33,82 & 59,03 & 90,08 & 127,51 & \\
\hline
\end{tabular}

$\mathrm{CV}=35,85 \%$. 
idade, quando valores médios aumentaram em 2,3 vezes. Estes resultados podem ser associados ao crescimento alométrico do pâncreas, que teve crescimento máximo nas duas primeiras semanas de idade.

O comportamento da atividade da amilase no presente estudo foi semelhante ao verificado por Pinchasov et al. (1990), que constatou que a atividade da amilase pancreática atingiu maior incremento na $2^{\mathrm{a}}$ semana de idade. Entretanto, Nitsan et al. (1991a,b) e Nir et al. (1993) observaram diminuição na atividade da amilase nas duas primeiras semanas de idade das aves. Este comportamento foi atribuído ao fato de que, nos primeiros dias de vida da ave, a absorção de nutrientes do saco vitelino pode interferir na produção enzimática (Nitsan et al., 1991a).

Apesar de não ter sido observada diferença significativa entre os valores médios de atividade enzimática das aves que receberam os alimentos testados, pode-se observar maior atividade de amilase pancreática para as aves que receberam a ração referencia $(79,65)$, seguida do FSO $(64,51)$, da SITV $(59,62)$ e da SIE $(56,62)$. Esse efeito pode ser explicado pelo fato de a ração ser balanceada de acordo com as exigências nutricionais das aves, enquanto os demais alimentos foram misturados à ração-referência, tornando-a desbalanceada. Deve-se considerar, também, que a presença e concentração do substrato dos alimentos, associadas à maturação dos órgãos digestivos, conforme a idade das aves são fatores que podem interferir na atividade das enzimas pancreáticas (Moran Jr., 1985;
Nitsan et al, 1991b; Sell et al., 1991). A atividade da amilase - uma enzima indutiva - depende da presença do substrato (Rodwell, 1990).

Os resultados da atividade da tripsina são apresentados na Tabela 5. Não houve interação significativa entre a idade das aves e os alimentos testados. Porém, houve aumento linear da atividade de tripsina, em função da idade ( $\left.Y=7,49+7,77 \mathrm{x} ; \mathrm{R}^{2}=0,98\right)$ e o período de maior evolução foi entre a $1^{\text {a }}$ e $2^{\text {a }}$ semanas de idade das aves, também associado ao crescimento alométrico do pâncreas.

O aumento da atividade de tripsina, de acordo com a idade das aves, também foi observado por Nitsan et al. (1991a,b), Sell et al. (1991) e Nir et al. (1993), em frangos de corte e galinhas de postura, sendo maior nas duas primeiras semanas. Entretanto, Krogdahl \& Sell (1989) e Pinchasov et al. (1990) não registraram alteração da atividade da tripsina, de acordo com a idade da ave.

A atividade enzimática da tripsina de 23,21 U/mg de proteína determinada para as aves tratadas com SIE foi significativamente superior aos valores determinados para o FSO $(14,73)$, SITV $(14,55)$ e ração $(16,76)$, que não diferiram entre si. Esse resultado pode ser explicado pelo fato de o processamento da soja por extrusão promover a desnaturação das moléculas protéicas, aumentando a digestibilidade da proteína. Conforme Penz Jr. (1994), quanto mais rígidas as ligações que mantêm a tridimensionalidade das proteínas, mais difícil é a ação das enzimas proteolíticas e mais baixa é sua digestibilidade.

\begin{tabular}{|c|c|c|c|c|c|c|}
\hline \multirow[t]{2}{*}{$\begin{array}{l}\text { Soja } \\
\text { Soybean }\end{array}$} & \multicolumn{5}{|c|}{$\begin{array}{c}\text { Idade (dias) } \\
\text { Age (days) }\end{array}$} & \multirow[t]{2}{*}{$\begin{array}{l}\text { Média } \\
\text { Mean }\end{array}$} \\
\hline & $1-7$ & $8-14$ & $15-21$ & $22-28$ & $35-42$ & \\
\hline $\begin{array}{l}\text { Farelo de soja + óleo } \\
\text { Soybean meal + oil }\end{array}$ & 1,39 & 7,19 & 14,88 & 22,99 & 27,19 & $14,73 b$ \\
\hline $\begin{array}{l}\text { Tostada } \\
\text { Toasted FFS }\end{array}$ & 1,43 & 2,05 & 7,28 & 21,31 & 40,66 & $14,55 b$ \\
\hline Extrusada & \multicolumn{5}{|c|}{ Extruded FFS } & $23,21^{\mathrm{a}}$ \\
\hline Reference diet & 1,86 & 5,29 & 18,37 & 21,71 & 36,55 & $16,76 b$ \\
\hline $\begin{array}{l}\text { Média } \\
\text { Mean }\end{array}$ & 1,69 & 5,56 & 16,11 & 24,58 & 38,62 & \\
\hline
\end{tabular}

Médias na coluna seguidas de letras diferentes são diferentes $(P<0,05)$ pelo teste de Tukey.

Means, within a column, followed by different letters are different $(P<.05)$ by Tukey test.

$\mathrm{CV}=33,35 \%$.

R. Bras. Zootec., v.33, n.4, p.924-935, 2004 
Na Tabela 6, são apresentados os dados da atividade da lipase pancreática. A análise comprova que houve interação significativa entre a idade das aves e os alimentos testados. Com o desdobramento da interação, observou-se efeito quadrático da idade na atividade de lipase para o FSO ( $\mathrm{Y}=-130,27+$ $\left.164,68 \mathrm{x}-13,10 \mathrm{x}^{2} ; \mathrm{R}^{2}=0,97\right)$, para a SIE $(Y=-235,19$ $\left.+293,97 x-29,89 x^{2} ; R^{2}=0,86\right)$ e para a ração $\left(\mathrm{Y}=-121,17+213,09 \mathrm{x}-20,59 \mathrm{x}^{2} ; \mathrm{R}^{2}=0,99\right)$. Com esses alimentos a atividade da lipase cresceu até a $2^{\text {a }}$ semana, tendendo a se estabilizar a partir da $3^{\text {a }}$ semana. Para a SITV, observou-se efeito linear $\left(Y=-76,22+92,96 x ; R^{2}=0,97\right)$, indicando que para cada fase houve aumento de 92,96 U/mg de proteína.

Assim como para a amilase e tripsina, a atividade de lipase também está associada ao crescimento alométrico do pâncreas. Escribano et al. (1988), Krogdahl \& Sell (1989), Sell et al. (1991), Nitsan et al. (1991b) e Nir et al. (1993) também constataram que a atividade da lipase cresceu com a idade das aves.

Com relação aos alimentos testados, verificou-se que o processo de extrusão afetou a produção de lipase somente na $4^{\mathrm{a}}$ semana de idade. Os valores determinados para as aves alimentadas com SIE mostraram-se superiores aos das aves alimentadas com SITV, FSO e ração, que foram semelhantes entre si. O fato de a SIE ter promovido maior atividade de lipase pode estar relacionado à maior exposição ao óleo, em decorrência do processo de extrusão, pois a presença do substrato é um fator que atua diretamente na atividade enzimática da lipase, a qual é indutiva (Rodwell, 1990). A influência da presença das gorduras nas dietas de aves, atuando como substrato, foi observada por Nitsan et al. (1974) e Nir \& Nitsan (1979).

Os valores médios dos coeficientes de digestibilidade do extrato etéreo aparente (CDEEAp) e verdadeiro (CDEEV) dos alimentos são apresentados nas Tabelas 7 e 8, respectivamente. Houve interação significativa entre a idade das aves e os alimentos testados para o CDEEAp e o CDEEV.

$O$ efeito da idade da ave na digestibilidade da gordura de todas as sojas e da ração teve comportamento quadrático, conforme as equações relacionadas nas Tabelas 7 e 8 . A digestibilidade da gordura do FSO e da SIE evoluiu até a $3^{\text {a }}$ semana de idade e permaneceu constante até a $6^{\text {a }}$ semana. Para a SITV, ocorreu decréscimo na digestibilidade a partir da $4^{\mathrm{a}}$ semana e, para a ração, a partir da $3^{\text {a }}$ semana.

Estes resultados são associados à taxa de crescimento do pâncreas e à atividade da lipase. Segundo Macari et al. (1994), na ave jovem, a absorção de gordura é limitada e, apenas quando a estrutura do enterócito alcança seu pleno desenvolvimento, é que a absorção de lipídeos se efetiva, o que ocorre após 2 ou 3 semanas de vida pós-natal, fase em que os mecanismos de digestão e absorção alcançam sua plenitude. Utilizando várias fontes de gorduras, Whitehead \& Fischer (1975) e Sell et al. (1986) também observaram aumento na digestibilidade das gorduras com o avanço da idade das aves.

Tabela 6 - Atividade da lipase pancreática (U/mg de proteína) segundo os tipos de soja e idade das aves

Table 6 - Effect of age and full fat soybeans on the lipase activity (U/mg of protein)

\begin{tabular}{|c|c|c|c|c|c|c|}
\hline \multirow{3}{*}{$\begin{array}{l}\text { Soja } \\
\text { Soybean }\end{array}$} & \multirow{2}{*}{\multicolumn{5}{|c|}{$\begin{array}{c}\text { Idade (dias) } \\
\text { Age (days) }\end{array}$}} & \multirow{3}{*}{$\begin{array}{l}\text { Média } \\
\text { Mean }\end{array}$} \\
\hline & & & & & & \\
\hline & $1-7$ & $8-14$ & $15-21$ & $22-28$ & $35-42$ & \\
\hline $\begin{array}{l}\text { Farelo de soja + óleo } \\
\text { Soybean meal + oil }\end{array}$ & $40,51 \mathrm{a}$ & $113,65 a$ & $237,95 a$ & $348,78 b$ & $378,00 a$ & 223,7 \\
\hline $\begin{array}{l}\text { Tostada } \\
\text { Toasted FFS }\end{array}$ & $42,16 a$ & $107,79 a$ & $213,10 a$ & $320,21 b$ & $389,65 a$ & 214,5 \\
\hline $\begin{array}{l}\text { Extrusada } \\
\text { Extruded FFS }\end{array}$ & $49,84 a$ & $130,32 a$ & 277,77a & $562,50 a$ & $430,81 a$ & 290,2 \\
\hline $\begin{array}{l}\text { Ração-referência } \\
\text { Reference diet }\end{array}$ & $36,43 a$ & $162,61 \mathrm{a}$ & $302,92 a$ & $359,48 b$ & $372,86 a$ & 246,8 \\
\hline $\begin{array}{l}\text { Média } \\
\text { Mean }\end{array}$ & 42,24 & 128,59 & 257,94 & 397,74 & 417,83 & \\
\hline
\end{tabular}

Médias na coluna seguidas de letras diferentes são diferentes $(P<0,05)$ pelo teste Tukey. Means within a column followed by different letters are different $(P<.05)$ by Tukey test. $\mathrm{CV}=26,54 \%$. 
Tabela 7 - Coeficientes de digestibilidade aparente do extrato etéreo (CDEEAp) das sojas, expressos em \%, determinados nas diferentes idades das aves alimentadas com diversos tipos de soja

Table 7 - Effect of age of birds and soybeans on apparent digestibility of fat

\begin{tabular}{lcccccc}
\hline $\begin{array}{l}\text { Soja } \\
\text { Soybean }\end{array}$ & \multicolumn{5}{c}{$\begin{array}{c}\text { Idade (dias) } \\
\text { Age (days) }\end{array}$} & $\begin{array}{c}\text { Média } \\
\text { Mean }\end{array}$ \\
\cline { 2 - 6 } & $1-7$ & $8-14$ & $15-21$ & $22-28$ & $36-42$ & \\
\hline $\begin{array}{l}\text { Farelo de soja + óleo } \\
\text { Soybean meal + oil }\end{array}$ & $80,67 \mathrm{a}$ & $87,69 \mathrm{~b}$ & $93,62 \mathrm{a}$ & $92,94 \mathrm{a}$ & $92,77^{\mathrm{a}}$ & 89,54 \\
$\begin{array}{l}\text { Tostada } \\
\text { Toasted FFS }\end{array}$ & $73,43 \mathrm{~b}$ & $80,98 \mathrm{c}$ & $79,92 \mathrm{~b}$ & $80,42 \mathrm{~b}$ & $77,69 \mathrm{~b}$ & 78,49 \\
$\begin{array}{l}\text { Extrusada } \\
\text { Extruded FFS }\end{array}$ & $85,50 \mathrm{a}$ & $93,40 \mathrm{a}$ & $95,87 \mathrm{a}$ & $95,30 \mathrm{a}$ & $95,77 \mathrm{a}$ & 93,17 \\
$\begin{array}{l}\text { Ração-referência } \\
\text { Reference diet }\end{array}$ & $71,15 \mathrm{~b}$ & $79,29 \mathrm{c}$ & $79,23 \mathrm{~b}$ & $79,23 \mathrm{~b}$ & $73,14 \mathrm{~b}$ & 77,36 \\
$\begin{array}{l}\text { Média } \\
\text { Mean }\end{array}$ & 77,69 & 85,34 & 88,34 & 86,97 & 84,24 & \\
\hline
\end{tabular}

Médias na coluna seguidas de letras diferentes são diferentes $(P<0,05)$ pelo teste Tukey. Means within a column followed by different letters are different $(P<.05)$ by Tukey test. $\mathrm{CV}=3,85 \%$.

Equações: (1) $Y=71,74+10,26 x-1,13 x^{2}, R^{2}=0,97 ;$ (2) $Y=69,02+6,41 x-0,83 x^{2}, R^{2}=0,76$ (3) $Y=79,51+7,85 x-0,87 x^{2}, R^{2}=0,90 ;$ (4) $Y=62,30+11,29 x-1,59 x^{2}, R^{2}=0,87$

Tabela 8 - Coeficientes de digestibilidade verdadeira do extrato etéreo (CDEEV) das sojas, expressos em \%, determinados nas diferentes idades das aves

Table 8 - Effect of age of birds and soybeans on true digestibility of fat

\begin{tabular}{|c|c|c|c|c|c|c|}
\hline \multirow[t]{2}{*}{$\begin{array}{l}\text { Soja } \\
\text { Soybean }\end{array}$} & \multicolumn{5}{|c|}{$\begin{array}{c}\text { Idade (dias) } \\
\text { Age (days) }\end{array}$} & \multirow[t]{2}{*}{$\begin{array}{l}\text { Média } \\
\text { Mean }\end{array}$} \\
\hline & $1-7$ & 8-14 & $15-21$ & $22-28$ & $36-42$ & \\
\hline Farelo de soja + óleo ${ }^{1}$ & $81,80 \mathrm{ab}$ & $88,07 b$ & $93,86 a$ & $93,89 a$ & $93,12 \mathrm{a}$ & 90,15 \\
\hline $\begin{array}{l}\text { Tostada }{ }^{2} \\
\text { Toasted FFS }\end{array}$ & $74,84 \mathrm{c}$ & $81,47 \mathrm{c}$ & $80,84 c$ & $80,84 b$ & $78,10 \mathrm{~b}$ & 79,12 \\
\hline $\begin{array}{l}\text { Extrusada }^{3} \\
\text { Extruded FFS }\end{array}$ & $86,41 a$ & $93,71 \mathrm{a}$ & $96,17 \mathrm{a}$ & $95,63 a$ & $96,17 \mathrm{a}$ & 93,62 \\
\hline $\begin{array}{l}\text { Ração-referência }{ }^{4} \\
\text { Reference diet }\end{array}$ & $76,74 \mathrm{bc}$ & $81,21 \mathrm{c}$ & $85,90 b$ & $81,43 b$ & $75,64 b$ & 80,18 \\
\hline $\begin{array}{l}\text { Média } \\
\text { Mean }\end{array}$ & 79,95 & 86,12 & 89,07 & 87,95 & 85,76 & \\
\hline
\end{tabular}

Médias, na coluna, seguidas de letras diferentes são diferentes $(P<0,05)$ pelo teste Tukey. Means, within a column, followed by different letters are different $(P<.05)$ by Tukey test. $\mathrm{CV}=3.26 \%$.

Equações: (1) $Y=73,64+9,70 x-1,08 x^{2} ; R^{2}=0,97 ;$ (2) $Y=70,98+5,63 x-0,74 x^{2} ; R^{2}=0,99$

(3) $Y=80,77+7,35 x-0,80 x^{2} ; R^{2}=0,91 ;$ (4) $Y=69,91+8,31 x-1,23 x^{2} ; R^{2}=0,86$

Com relação aos alimentos, houve diferenças nos coeficientes de digestibilidade do extrato etéreo em todas fases de idade. Os CDEEAp e CDEEV da SIE e do FSO, alimentos com maior disponibilidade de óleo, não diferiram entre si, mas foram superiores à digestibilidade da SITV e da ração-referência, à qual não foi adicionado óleo.

O tipo de processamento térmico das sojas pro- porcionou diferenças na digestibilidade dos nutrientes. Em todas as idades, o processo de extrusão mostrou-se superior à tostagem, em razão da exposição maior do óleo à ação da lipase pancreática e aos sais biliares, facilitando a digestão e absorção de lipídeos. No entanto, no processo de tostagem, em função da disponibilidade do óleo ser limitada, os coeficientes de digestibilidade do EE foram seme- 
lhantes aos da ração, que apresentou baixo teor de extrato etéreo, cerca de 2,18 a 2,36\%, dificultando o aproveitamento pelas aves.

As pequenas diferenças entre os CDEEAp e CDEEV são atribuídas às perdas endógenas e metabólicas que, nas condições de consumo voluntário, são menores quando comparadas à metodologia de alimentação forçada, em que o consumo de alimento também é menor.

Os valores médios dos coeficientes de digestibilidade da matéria seca aparente (CDMSAp) e verdadeiro (CDMSV) encontram-se nas Tabelas 9 e 10 , respectivamente.

Para ambos os parâmetros, houve interação significativa entre a idade das aves e os alimentos testados. O efeito da idade da ave sobre o CDMSAp e o CDMSV resultaram em equações cúbicas e linear para a SIE. Para a SITV e a ração os CDMSAp não foram influenciados pela idade.

Por outro lado, houve diferenças significativas entre as sojas avaliadas. Ambos os coeficientes de digestibilidade da matéria seca da ração-referência foram superiores em relação aos demais alimentos testados (Tabelas 9 e 10). Este resultado é explicado

Tabela 9 - Coeficientes de digestibilidade aparente da matéria seca das sojas, expressos em \%, determinados em cada idade das aves

Table 9 - Effect of age of birds and soybeans on apparent digestibility of dry matter

\begin{tabular}{|c|c|c|c|c|c|c|}
\hline \multirow{3}{*}{$\begin{array}{l}\text { Soja } \\
\text { Soybean }\end{array}$} & \multirow{2}{*}{\multicolumn{5}{|c|}{$\begin{array}{l}\text { Idade (dias) } \\
\text { Age (days) }\end{array}$}} & \multirow{3}{*}{$\begin{array}{l}\text { Média } \\
\text { Mean }\end{array}$} \\
\hline & & & & & & \\
\hline & $1-7$ & $8-14$ & $15-21$ & $22-28$ & $36-42$ & \\
\hline $\begin{array}{l}\text { Farelo de soja + óleo }{ }^{1} \\
\text { Soybean meal + oil }\end{array}$ & $65,43 a$ & $55,07 b$ & $56,91 c$ & $59,23 b$ & $47,19 \mathrm{c}$ & 56,76 \\
\hline $\begin{array}{l}\text { Tostada } \\
\text { Toasted FFS }\end{array}$ & $65,37 a$ & $60,10 \mathrm{~b}$ & 59,39bc & $60,55 b$ & $60,12 b$ & 61,11 \\
\hline $\begin{array}{l}\text { Extrusada }^{2} \\
\text { Extruded FFS }\end{array}$ & $65,63 a$ & $62,25 b$ & $65,33 b$ & $59,64 b$ & $56,92 b$ & 61,95 \\
\hline $\begin{array}{l}\text { Ração-referência } \\
\text { Reference diet }\end{array}$ & $69,94 a$ & $70,61 a$ & $69,81 a$ & $70,57 a$ & $71,80 a$ & 70,55 \\
\hline $\begin{array}{l}\text { Média } \\
\text { Mean }\end{array}$ & 66,59 & 62,01 & 62,86 & 62,50 & 59,01 & \\
\hline
\end{tabular}

Médias, na coluna, seguidas de letras diferentes são diferentes $(P<0,05)$ pelo teste Tukey. Means, within a column, followed by different letters are different $(P<.05)$ by Tukey test. $\mathrm{CV}=7,70 \%$.

Equações: (1) $Y=92,12-37,82 x+12,16 x^{2}-1,18 X^{3}, R^{2}=0,99 ; \quad(2) Y=67,37-1,69 x, R^{2} 0,76$

Tabela 10 - Coeficientes de digestibilidade verdadeiro da matéria seca, expressos em \% MS das sojas, segundo a idade das aves

Table 10 - Effect of age of birds and soybeans on true digestibility of dry matter

\begin{tabular}{|c|c|c|c|c|c|c|}
\hline \multirow[t]{2}{*}{$\begin{array}{l}\text { Soja } \\
\text { Soybean }\end{array}$} & \multicolumn{5}{|c|}{$\begin{array}{c}\text { Idade (dias) } \\
\text { Age (days) }\end{array}$} & \multirow{2}{*}{$\begin{array}{l}\text { Média } \\
\text { Mean }\end{array}$} \\
\hline & $1-7$ & $8-14$ & $15-21$ & $22-28$ & $36-42$ & \\
\hline $\begin{array}{l}\text { Farelo de soja + óleo }{ }^{1} \\
\text { Soybean meal }+ \text { oil }\end{array}$ & $68,93 a$ & $57,85 b$ & $57,83 c$ & $62,79 b$ & $50,85 c$ & 64,73 \\
\hline $\begin{array}{l}\text { Tostada } \\
\text { Toasted FFS }\end{array}$ & $69,17 \mathrm{a}$ & $63,20 b$ & $60,30 \mathrm{bc}$ & $64,45 b$ & $63,73 b$ & 64,17 \\
\hline $\begin{array}{l}\text { Extrusada } \\
\text { Extruded FFS }\end{array}$ & $68,59 a$ & $64,62 b$ & 66,19ab & $63,35 b$ & $60,93 b$ & 59,65 \\
\hline $\begin{array}{l}\text { Ração-referência } \\
\text { Reference diet }\end{array}$ & $72,41 \mathrm{a}$ & 72,60a & 70,55a & 74,03a & $75,34 a$ & 72,98 \\
\hline $\begin{array}{l}\text { Média } \\
\text { Mean }\end{array}$ & 69,77 & 64,56 & 63,72 & 66,15 & 62,71 & \\
\hline
\end{tabular}

Médias na coluna seguidas de letras diferentes são diferentes $(P<0,05)$ pelo teste Tukey. Means within a column followed by different letters are different $(P<.05)$ by Tukey test.

$\mathrm{CV}=7,33 \%$ Equação: (1) $\mathrm{Y}=100,45-44,17 \mathrm{x}+14,06 \mathrm{x}^{2}-1,34 \mathrm{x}^{3}, \mathrm{R}^{2}=0,99$ 
pelo fato de a ração-referência ser balanceada.

A pequena diferença entre os valores do CDMSAp e do CDMSV decorreu da correção pelas perdas endógenas e metabólicas.

Os resultados encontrados no presente estudo mostraram-se superiores aos de Café (1993), trabalhando com pintos aos 21 dias de idade, tanto para a SIE de $58 \%$ quanto para o FSO de $52 \%$, sendo semelhantes ao determinado para SITV de 60,4\%.

Os resultados de energia metabolizável aparente corrigida pelo balanço de nitrogênio (EMAn) e de energia metabolizável verdadeira corrigida pelas perdas endógenas e metabólicas (EMVn) são apresentados nas Tabelas 11 e 12. A análise estatística mostrou que, tanto para a EMAn quanto para a EMVn, houve interação significativa entre a idade da ave e as sojas testadas.

Tabela 11 - Valores de energia metabolizável aparente corrigida (kcal/kg MS) das sojas, determinados em cada idade das aves

Table 11 - Effect of age of birds and soybeans on apparent metabolizable energy corrected by nitrogen balance ( $\mathrm{kcal} / \mathrm{kg}$ of dry matter)

\begin{tabular}{|c|c|c|c|c|c|c|}
\hline \multirow[t]{2}{*}{$\begin{array}{l}\text { Soja } \\
\text { Soybean }\end{array}$} & \multicolumn{5}{|c|}{$\begin{array}{c}\text { Idade (dias) } \\
\text { Age (days) }\end{array}$} & \multirow[t]{2}{*}{$\begin{array}{l}\text { Média } \\
\text { Mean }\end{array}$} \\
\hline & $1-7$ & $8-14$ & $15-21$ & $22-28$ & $36-42$ & \\
\hline Farelo de soja + óleo & 3.883a & $3.756 b$ & $4.151 b$ & $3.956 b$ & $3.699 a$ & 3.889 \\
\hline $\begin{array}{l}\text { Soybean meal + oil } \\
\text { Tostada } \\
\text { Toasted FFS }\end{array}$ & $3.724 a$ & $3.749 b$ & $3.893 b$ & $3.796 b$ & 3.659a & 3.764 \\
\hline $\begin{array}{l}\text { Extrusada }^{1} \\
\text { Extruded FFS }\end{array}$ & $4.079 a$ & $4.149 \mathrm{a}$ & $4.960 \mathrm{a}$ & $4.459 \mathrm{a}$ & $3.975 \mathrm{a}$ & 4.324 \\
\hline $\begin{array}{l}\text { Ração-referência } \\
\text { Reference diet }\end{array}$ & $2.906 \mathrm{~b}$ & $2.957 c$ & $3.045 c$ & $3.076 \mathrm{c}$ & $3.077 \mathrm{~b}$ & 3.012 \\
\hline $\begin{array}{l}\text { Média } \\
\text { Mean }\end{array}$ & 3.648 & 3.653 & 4.012 & 3.822 & 3.602 & \\
\hline
\end{tabular}

Médias na coluna seguidas de letras diferentes são diferentes $(P<0,05)$ pelo teste de Tukey.

Means within a column followed by different letters are different $(P<.05)$ by Tukey test.

C.V. $=6,18 \%$

Equação: (1) $\mathrm{Y}=3.373,55+735,51 \mathrm{x}-106,24 \mathrm{x}^{2} ; \mathrm{R}^{2}=0,65$

Tabela 12 - Valores de energia metabolizável verdadeira corrigida (kcal/kg MS) das sojas, determinados em cada idade das aves

Table 12 - Effect of age of birds and soybeans on true metabolizable energy corrected by nitrogen balance ( $\mathrm{kcal} / \mathrm{kg}$ of dry matter)

\begin{tabular}{|c|c|c|c|c|c|c|}
\hline \multirow[t]{2}{*}{$\begin{array}{l}\text { Soja } \\
\text { Soybean }\end{array}$} & \multicolumn{5}{|c|}{$\begin{array}{l}\text { Idade (dias) } \\
\text { Age (days) }\end{array}$} & \multirow[t]{2}{*}{$\begin{array}{l}\text { Média } \\
\text { Mean }\end{array}$} \\
\hline & $1-7$ & $8-14$ & $15-21$ & $22-28$ & $36-42$ & \\
\hline $\begin{array}{l}\text { Farelo de soja + óleo } \\
\text { Soybean meal + oil }\end{array}$ & 3.956a & $3.812 b$ & $4.204 b$ & $4.005 b$ & $3.751 \mathrm{a}$ & 3.946 \\
\hline $\begin{array}{l}\text { Tostada } \\
\text { Toasted FFS }\end{array}$ & $3.827 a$ & $3.812 b$ & $3.945 b$ & $3.852 b$ & $3.711 \mathrm{a}$ & 3.829 \\
\hline $\begin{array}{l}\text { Extrusada }^{1} \\
\text { Extruded FFS }\end{array}$ & $4.156 a$ & 4.195a & 5.008a & $4.510 \mathrm{a}$ & 4.032a & 4.380 \\
\hline $\begin{array}{l}\text { Ração-referência } \\
\text { Reference diet }\end{array}$ & $2.968 \mathrm{~b}$ & $2.977 \mathrm{c}$ & $3.086 c$ & $3.122 \mathrm{c}$ & $3.127 b$ & 3.056 \\
\hline $\begin{array}{l}\text { Média } \\
\text { Mean }\end{array}$ & 3.727 & 3.699 & 4.061 & 3.872 & 3.655 & \\
\hline
\end{tabular}

R. Bras. Zootec., v.33, n.4, p.924-935, 2004 
Com o desdobramento da interação, observou-se efeito quadrático na EMAn e EMVn da SIE, em função da idade. Conforme equações apresentadas nas Tabelas 11 e 12, a energia metabolizável aumentou até a $3^{\mathrm{a}}$ semana, diminuindo a partir da $4^{\mathrm{a}}$ semana. Para o FSO, apesar de não ter ocorrido diferença significativa, os valores de EM apresentaram a mesma tendência verificada para os valores da SIE. Entretanto, os valores obtidos para a SITV e para a ração não sofreram variação conforme a idade da ave.

Os menores valores de EM determinados nas três primeiras semanas de idade podem ser justificados pelos baixos CDEE verificados nessa fase, assim como pelas atividades da amilase e da lipase, indicando que, nestas semanas, a capacidade de digestão das aves não está totalmente desenvolvida, limitando o aproveitamento dos nutrientes das dietas, principalmente as gorduras.

Normalmente, a EM dos alimentos aumenta com a idade até atingir o máximo, permanecendo nesse nível com pequenas variações (Sell et al., 1986). Desse modo, a queda da EM a partir da $4^{\mathrm{a}}$ semana de idade verificada no presente estudo para SIE e FSO pode ser atribuída ao fato de que cada ensaio foi conduzido separadamente, podendo ter havido influência da condição experimental, o que também resultou em $\mathrm{R}^{2}$ relativamente baixo das equações obtidas para SIE.

Quanto aos tipos de sojas testados, foram verificadas diferenças na EMAn (Tabela 11) e EMVn (Tabela 12) em todas as idades. Na $1^{\text {a }}$ e na $6^{\text {a }}$ semanas, pode-se observar que os valores determinados para a SIE, SITV e para o FSO foram semelhantes entre si e superiores aos determinados para a ração. Na $2^{\text {a }}$, $3^{\text {a }}$ e $4^{\text {a }}$ semanas, os valores de EMAn e EMVn determinados para a SIE foram superiores aos determinados para as demais sojas. Os valores de EM do FSO e da SITV foram semelhantes e superiores aos determinados para a ração. O processo de extrusão, por tornar mais disponível o conteúdo lipídico do grão de soja, promoveu melhor aproveitamento da gordura e do amido, elevando a EM da soja.

Comparando com os resultados da literatura (Wiseman, 1983; NRC, 1994; EMBRAPA, 1991; Albino et al., 1992; Café, 1993), pode-se observar que os valores médios de EMAn e de EMVn da SIE, SITV, FSO determinados neste trabalho foram próximos aos da literatura. As pequenas variações são normais, se consideradas as diversas condições experimentais.

Os valores de EMVn determinados para todas as sojas foram ligeiramente superiores aos de EMAn, em decorrência da correção pelas perdas endógenas e metabólicas. As pequenas diferenças podem ser explicadas pela menor influência da energia fecal metabólica e da urinária endógena em função do total de energia excretada, quando se utiliza a metodologia de coleta total de excretas (Shires et al., 1980).

\section{Conclusões}

O máximo crescimento alométrico do pâncreas coincidiu com o maior incremento na produção das enzimas digestivas.

A atividade da lipase pancreática foi influenciada pela exposição à gordura presente nas sojas avaliadas.

A digestibilidade da gordura variou em função da idade das aves e foi associada com a atividade da lipase.

$\mathrm{O}$ aproveitamento da energia dos alimentos foi afetado pela idade das aves, em função da dependência da produção das enzimas digestivas.

Com a idade dos frangos de corte o desenvolvimento do pâncreas se completou aumentando a produção das enzimas digestivas e, conseqüentemente, melhorando o aproveitamento da energia das sojas testadas.

O tipo de processamento das sojas também afeta a disponibilidade de energia para as aves.

A soja integral extrusada apresentou valores de EM superiores ao farelo de soja com adição de óleo e à soja integral tostada pelo vapor.

Na formulação de rações utilizando soja integral, é importante levar em conta o maior aproveitamento da energia com o aumento da idade da ave, assim como o tipo de processamento.

\section{Literatura Citada}

ALBINO, L.T.F.; FIALHO, E.T.; BRUM, P.A.R. et al. Determinação dos valores energéticos de alguns alimentos para aves. In: REUNIÃO ANUAL DA SOCIEDADE BRASILEIRA DE ZOOTECNIA, 29., 1992 , Lavras. Anais... Lavras: Sociedade Brasileira de Zootecnia, 1992. p.330.

ASSOCIAÇÃO NACIONAL DOS FABRICANTES DE RAÇÕES - ANFAR. Matérias-primas para alimentação animal. Padrão ANFAR. 4.ed. São Paulo: ANFAR, 1985. 65p. ASSOCIAÇÃO NACIONAL DOS FABRICANTES DE RAÇÕES - ANFAR. Métodos analíticos de controle de alimentos para uso animal. São Paulo: ANFAR, 1992. p.1-2.

ARABA, M.; DALE, N.M. Evaluation of protein solubility as an indicator of overprocessing soybean meal. Poultry Science, v.69, n.1, p.76-83, 1990a.

ARABA, M.; DALE, N.M. Evaluation of protein solubility as an indicator of underprocessing soybean meal. Poultry Science, v.69, n.10, p.1749-1752, 1990b. 
BERNFELD, P. Amylases, alfa e beta. In: COLOWICK, S.; KAPLAN, N. (Eds.). Methods in enzymology. New York: Academic Press, 1955. p.149-155.

CAFÉ, M.B. Estudo do valor nutricional da soja integral processada para aves. Jaboticabal: Universidade Estadual Paulista, 1993. 97p. Dissertação (Mestrado em Zootecnia) Universidade Estadual Paulista, 1993.

EMPRESA BRASILEIRA DE PESQUISA E AGROPECUÁRIA - EMBRAPA. Tabela de composição química e valores energéticos de alimentos para suínos e aves. 3.ed. Concórdia: Embrapa Suínos e Aves, 1991. 97p.

ESCRIBANO, F.; RAHN, B.E.; SELL, J.L. Development of lipase activity in yolk membrana and pancreas of young turkeys. Poultry Science, v.67, p.1089-1097, 1988.

FISHER, C. Fat deposition in broilers. In: WISEMAN, J. (Ed.). Fats in animal nutrition. Nottinghan:Butterworths, 1984. p.437-470.

HARTREE, E.F. Determination of protein: a modification of the Lowry method that gives a linear photometric response. Analitical Biochemistry, v.48, p.422-427, 1972.

JUNQUEIRA, R.G.; SGARBIERI, V.C. Isolation and general properties of lectins from the bean (Phaseolus vulgaris,L.). Journal Food Biochemistry, v.5, p.165-179, 1981.

KAKADE, M.L.; SIMONS, N.; LIENER, I.E. Determination of trypsin inhibitor activity of soy products: a collaborative analysis of an improved procedure. Cereal Chemistry, v.51, n.3, p.377-382, 1974.

KAKADE, M. L., RACKIS, J. J.; MCGHEE, J. G. An evaluation of natural vc sinthetic substracts for measuring the anti tryptic activity of soy bean samples. Cereal Chemistry, v.46, p.518-526, 1969.

KATANGOLE, J.B.D.; MARCH, B.E. Fat utilization in relation to intestinal fatty acid binding protein and bile salts in chicks of different ages and different genetic sources. Poultry Science, v.59, p.819-827, 1980.

KROGDAHL, A.; SELL, J.L. Influence of age on lipase, amylase and protease activities in pancreatic tissue and intestinal contents of young turkeys. Poultry Science, v.68, p.15611568, 1989.

MACARI, M.; FURLAN, R.; GONZALES, E. Fisiologia aviária aplicada à frangos de corte. Jaboticabal: FUNEP, 1994. 296p.

MORAN JR., E.T. Digestion and absorption of carbohydrates in fowl and the events through perinatal development. Journal Nutrition, v.115, p. 665-674, 1985.

NATIONAL RESEARCH COUNCIL - NRC. Board on Agriculture. Committee on Animal Nutrition. Subcommittee on Poultry Nutrition. 19.ed. Washington D.C.: National Academy Press, 1994. 155p.

NIR, I; NITSAN, Z.; MAHAGNA, M. Comparative growth and development of the digestive organs and of some enzymes in broiler and egg type chicks after hatching. British Poultry Science, v.34, p.523-532, 1993.
NIR, I.; NITSAN, Z. Metabolic and anatomical adaptations of light-bodied chicks to intermitent feeding. British Poultry Science, v.20, p.61-72, 1979.

NITSAN, Z.; DUNNINGTON, E.A.; SIEGEL, P.B. Organ growth and digestive enzyme levels to fifteen days of age in lines of chickens differing in body weigth. Poultry Science, v.70, p.2040-2048, 1991a.

NITSAN, Z.; DROR, Y.; SHAPIRA, N. The effect of forcefeeding on enzymes of liver, kidney, pancreas and digestive tract of chicks. British Journal Nutrition, v.32, p.241-271, 1974.

NITSAN, Z.; EN-AVRAHAM, G.; ZOREF, Z. et al. Growth and development of the digestive organs and some enzymes in broiler chicks after hatching. British Poultry Science, v.32, p.515-523, 1991b.

PENZ JR., A.M. Digestão e absorção de proteínas e aminoácidos. In: Fisiologia da digestão e absorção das aves. Campinas: APINCO, 1994. p.59-69.

PINCHASOV, Y.; NIR, I.; NITSAN, Z. Metabolic and anatomical adaptations of heavy-bodied chicks to intermitent feeding. 2. Pancreatic digestive enzymes. British Poultry Science, v.31, p.769-777, 1990.

RODWELL, V.M. Enzimas: regulação da atividade. In: HARPER, H.A. (Ed.) Bioquímica. São Paulo: Ateneu, 1990. p.84-94.

SARDA, L.; DESNUELLE, P. Action de la lipase pancréatique sur les esters en emulsion. Biochimistry Biophysic Acta, v.30, p.513-521, 1958.

SELL, J. L.; ANGEL, C.R.; PIQUER, F.J. et al. Developmental patterns of selected characteristics of the gastrointestinal tract of young turkeys. Poultry Science, v.70, p.1200-1205, 1991.

SELL, J. L.; KROGDHAL, A.; HANYU, N. Influence of age on utilization of supplemental fats by young turkeys. Poultry Science, v.65, p.546-554, 1986.

SHIRES, A.; ROBLEE, A. R.; HARDIN, R. T. et al. Effect of the age of chickens on the true metabolizable energy values of feed ingredients. Poultry Science, v.59, p.396-403, 1980.

SILVA, D.J. Análise de alimentos: métodos químicos e biológicos Viçosa, MG: Universidade Federal de Viçosa, 1981. 166p.

WHITEHEAD, G.C.; FISHER, C. The utilization of various fats by turkey of different ages. British Poultry Science, v.16, p.481-485, 1975.

WISEMAN, J. Utilization of full-fat soya beans and soya beans oil in diets for livestock. In: SPAIN CONFERENCE ON SOY PROTEIN UTILIZATION, 1983, Madrid. Proceedings... Madrid: 1983. 